\title{
TECNOLOGIA E INDUSTRIALIZAÇÂO NA CONSTRUÇÃO: AS CHAVES PARA LIDAR COM O DECLÍNIO DO NÍVEL DE PRODUTIVIDADE E BAIXA QUALIDADE DOS ATIVOS NA INDÚSTRIA
}

\section{TECHNOLOGY AND INDUSTRIALIZATION IN CONSTRUCTION: THE KEYS TO DEALING WITH THE DECLINE OF THE LEVEL OF PRODUCTIVITY AND LOW QUALITY OF ASSETS IN THE INDUSTRY}

\author{
Alexandre Victor Silva Pinheiro, \\ Acadêmico do 8o período em Engenharia Civil pela Alfa Unipac, Teófilo Otoni, Brasil. \\ E-mail: alexandrepinheiro.982@gmail.com
}

Pedro Emílio Amador Salomão, Doutor e Professor de Quimica pela Alfa Unipac, Teófilo Otoni, Brasil.

E-mail: pedroemilioamador@yahoo.com.br

Recebido: 10/11/2020 - Aceito: 27/11/2020

\section{Resumo}

A industrialização da construção (ic) promove o avanço dos processos de construção empregando mecanização e automação. Existem várias vantagens decorrentes da industrialização da construção, como aumento da produtividade do trabalho, substituição de processos intensivos de trabalho por máquinas, acompanhamento rápido da taxa de construção, redução de custos e melhoraria da qualidade geral. $\mathrm{A}$ industrialização é uma tendência significativa do avanço científico e técnico na construção e evidencía como a tecnologia está mudando a maneira como estruturas são projetadas e executadas. Este trabalho objetiva, por meio de pesquisas bibliográficas e webgráficas, expor as vantagens, limitações, bem como o potencial da injeção de tecnologia e industrialização dos processos convencionais na área da construção civil.

Palavras-chave: tecnologia; inovação; industrilização; construção.

\begin{abstract}
Construction industrialization (ci) promotes the advancement of construction processes using mechanization and automation. There are several advantages resulting from the industrialization of construction, such as increased labor productivity, replacement of labor intensive processes by machines, rapid monitoring of the construction rate, cost reduction and improvement of the overall quality. Industrialization is a significant trend in scientific and technical progress in construction and highlights how technology is changing the way structures are designed. This work aims, through bibliographic and webgraphic research, to expose
\end{abstract}


the advantages, limitations, as well as the potential of the injection of technology and industrialization of conventional processes in the area of civil construction.

Keywords: technology; innovation; industrialization; construction.

\section{Introdução}

A indústria da construção está entre os setores primários menos digitalizados do país, e quase todos os processos são repetitivos e trabalhosos. Grandes projetos normalmente se estendem $20 \%$ além da conclusão inicial data, e geralmente terminam $80 \%$ acima do orçamento inicial (LIMA, 2016). Além disso, é notorio o baixo ou inexistente desenvolvimento de produtividade na industria, bem como a baixa qualidade inversamente porporcional aos custos de construção. A baixa adesão e adaptação do setor a processos e tecnologias inovadoras podem ser fatores chave contribuintes para estes problemas.

No entanto, a indústria da construção não é completamente imune á globalização e a certos avanços tecnologicos. A mesma progrediu ao longo dos anos, e o futuro dos projetos e da construção exigirá a integreção de todas as partes interessadas, proprietários, designers, engenheiros, fabricantes e contratados, para adotar novas metodologias em seus processos, regulamentos e conjuntos de habilidades para prosperar na nova era da digitalização.

Foi projetado que até 2035 a maioria dos edifícios será construída usando a construção industrializada, utilizando a experiência da manufatura em produção em massa e construção capacidade de projetar e construir um produto complexo altamente personalizado.

A construção industrializada tem sido recomendada como resposta ao declínio do nível de produtividade e a baixa qualidade dos ativos do setor.

\section{Tendências}

O processo da Industrialização da Construção (IC) inclui o uso extensivo de tecnologia avançada, desde a pré-fabricação de grandes elementos de construção em fábricas externas, até a adaptação da construção em um processo de montagem mecanizada e a contínua instalação destes conjuntos ou peças pré-fabricadas. Uma combinação de vários avanços tecnológicos podem ser incorporados nos processos de construção modificando os layouts e a manufatura contornando infames problemas que definem a indústria da construção hoje. 
SmartArt1 - Objetivos as Industrialização.

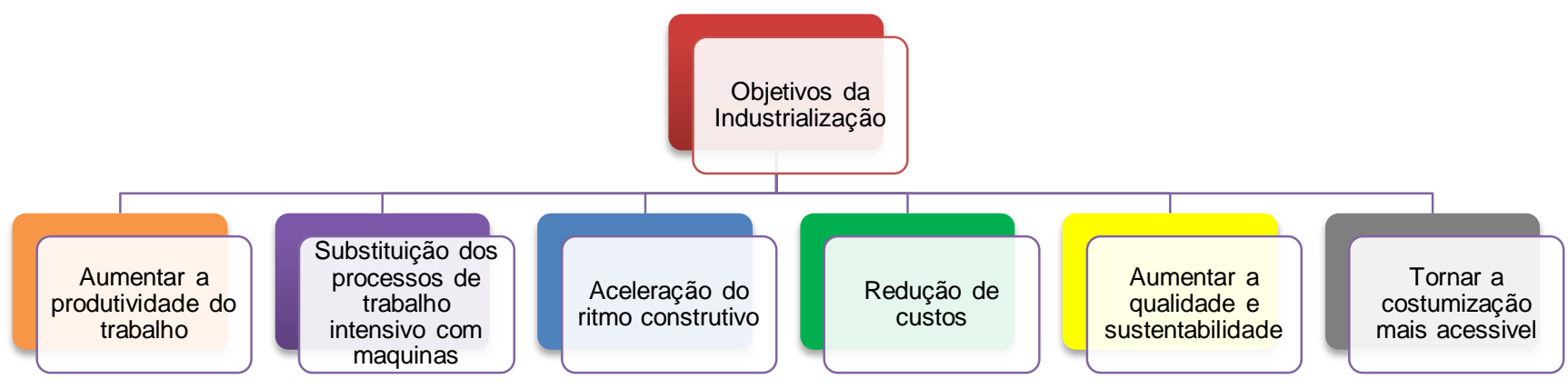

(Fonte: Autor, realizado em 14/05/2020)

\section{Tipos de processos de industrilização das construção Civil}

\subsection{Pré-fabricação}

A pré-fabricação é a construção externa de elementos, em uma fábrica, de onde são transportados para um local para montagem e instalação. A pré-fabricação na construção data em meados do século XIX, no entanto, ainda não atingiu ampla adoção no setor.

Os sistemas de pré-fabricação podem ser divididos em duas categorias: construção modular e painéis. Na construção modular, o metodo construtivo é essencialmente realizado em uma fábrica, com módulos em forma de caixa separados e, em seguida, transportado e instalado no local. Já na construção em painel, os componentes estruturais do edifício são construídos em uma fábrica e transportado no local para montagem.

A vantagem da pré-fabricação é a resolução de muitos dos problemas associados a métodos tradicionais de construção, como mão de obra intensiva qualificada, qualidade variável, ineficiências de produtos e processos, e altos impactos ambientais. Muito disso, devido a conclução dos elementos construtivos em fábricas, permitindo o uso de máquinas automatizadas, o que evita atrasos no projeto devido a, por exemplo, indisponibilidades de trabalho. Além disso, o emprego de equipamentos inovadores resulta em melhor qualidade do produto, eficiência 
aprimorada e, finalmente, redução de custos. Outro fator importanto é que a elaboração destes tais elementos em ambientes controlados reduz o desperdício de construção através da adoção de processos sustentáveis.

"Substituir processos artesanais por componentes produzidos na indústria e que são apenas montados nos canteiros é imperativo, da mesma forma que inovar seguindo as três dimensões da sustentabilidade (econômica, social e ambienta)." (DONIAK, 2012).

\subsection{Impressão 3D}

Na linha de frente da fabricação digital está a Additive Manufacturing (AM), comumente conhecida como Impressão 3D, que é a produção de objetos e estruturas a partir de constantes depósitos de materiais por camadas.

A indústria da construção começou a explorar a AM como uma emergente tecnologia de construção. Com o AM, é possível ir diretamente de um modelo 3D de um objeto a um produto acabado, usando uma ampla variedade de materiais, como aço, vidro, cerâmica, polímero, concreto e muito mais, processo este totalmente automatizado.

Uma das vantagens convidativas da impressão 3D é a capacidade de criar modelos personalizados, componentes complexos e exclusivos. Os contratados podem fornecer soluções ideais para projetos com desperdício mínimo e sem as restrições dos componentes, padrões da construção. O avanço desta tecnologia oferece ao mercado, estruturas esteticamente mais agradáveis e otimizadas, usando design generativo, bem como o desenvolvimento de novos materiais e processos.

"A inovação nesse setor busca aumentar a velocidade de produção, redução de custos, além de propor a sustentabilidade. Dessa forma, o avanço da tecnologia no setor auxilia no gerenciamento da obra e aumento da produtividade." (VIA, 2019)

\subsection{Robótica}

Robótica é a ciência de projetar, construir e aplicar robôs na realização trabalhos incorporando o conhecimento e a criatividade de diversas aréas da engenharia como, mecânica, elétrica, informática, industrial e de manufatura.

Os robôs, desde o começo do século XXI, vem sendo, geralmente, utilizados 
para realização uma gama limitada de tarefas monótonas, principalmente no manuseamento básico de materiais e componentes. No entanto, cada vez mais, juntamente com as pequisas e investimentos, o mercado cresce. As tecnologias robóticas emergentes usadas na indústria da construção, hoje, incluem robôs de demolição, robôs de impressão 3D, estações totais robóticas, rovers e scanners a laser, drones robóticos, robôs que executam alvenaria, robôs de solda, exoesqueletos, robôs empilhadeiras, robôs para obras rodoviárias e até mesmo humanoides. (LIMA, 2019)

A robotica emprega processos sincronizados que visam facilitar o trabalho, de seres humanos, em tarefas perigosas, cansativas ou que exigem grande esforço. Os robos podem ser conectados a redes de sensores, possibilitando coletas de dados em tempo real. Este feedback enviado ao sistema de controle, pode ser analisado visando o aperfeiçoamento do processo, melhorando assim a eficiencia e precisão durante o processo.

"Os robôs que, muito em breve devem ser mais comuns nos canteiros de obras, são desenvolvidos com avançado sistema de inteligência artificial, onde o computador programa tudo o que a máquina deve fazer, sem precisar de qualquer tipo de auxílio humano." (Overbr, 2019)

Figura 1 - FESTO Robotics.

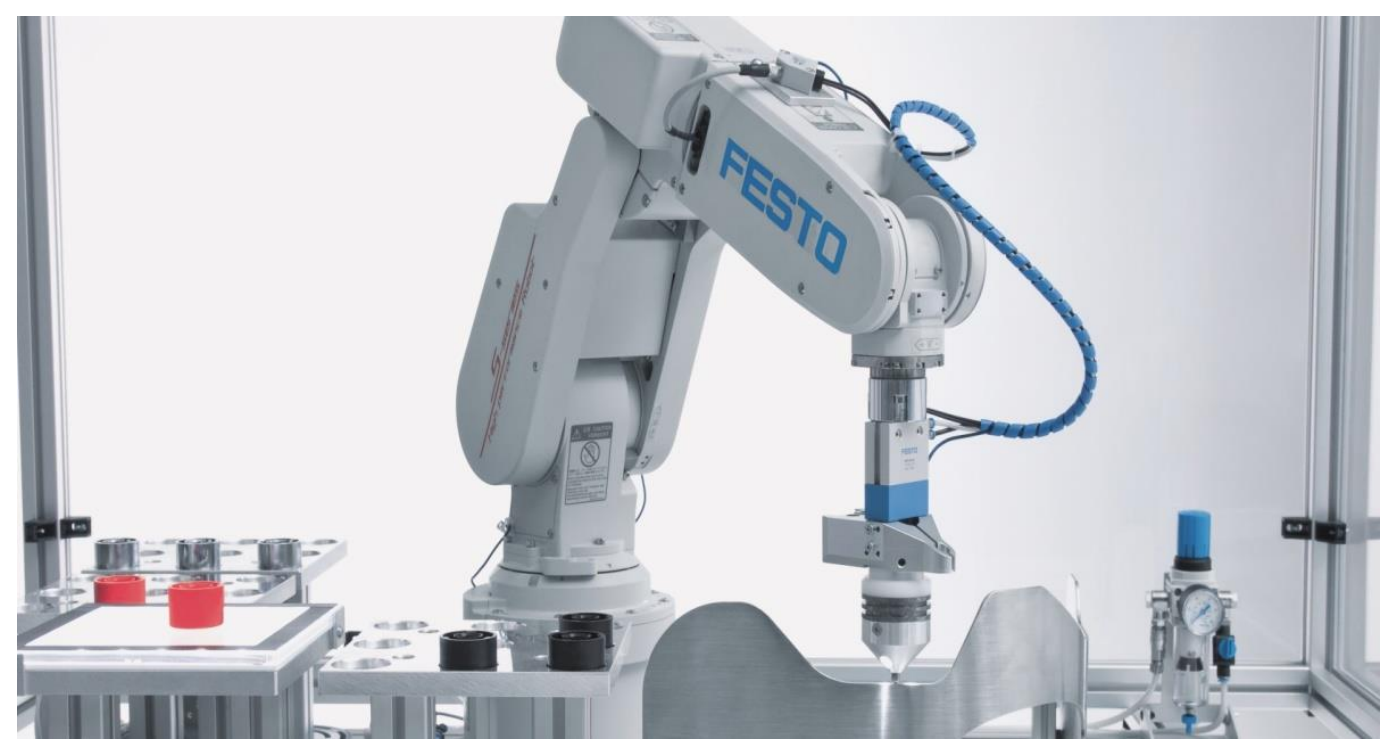

(Fonte: site festo.com, acesso em 07/09/2020) 


\subsection{Bim}

Atualmente, na indústria da construção, grandes quantidades de dados altamente estruturados estão sendo produzidos através do BIM (Building Information Modeling) e de outras ferramentas de tecnologia do projeto. A indústria, atualmente, lida com um enorme volume de dados sintetizados, e este volume só tem a tendência de intensificar exponencialmente já que tecnologias como redes de sensores são cada vez mais comoditizadas. (Thórus Engenharia, 2020)

Big data e análise preditiva são definidas pela capacidade de processar grandes quantidades de dados e extrair informações úteis do banco de dados. Essa tendência abriu as portas para um nova área na construção chamada "Inteligência de Construção".

A Inteligência de Construção é a capacidade de prever o futuro da construção atraves da mineração dos dados gerados a partir de inúmeros projetos. Analisando os dados em busca de padrões atraves de várias fontes podem ajudar um contratado a identificar várias tendências do projeto, como o base para superestimação nas propostas. (LIMA, 2018)

Figura 2 - BIM (Building Information Modeling).

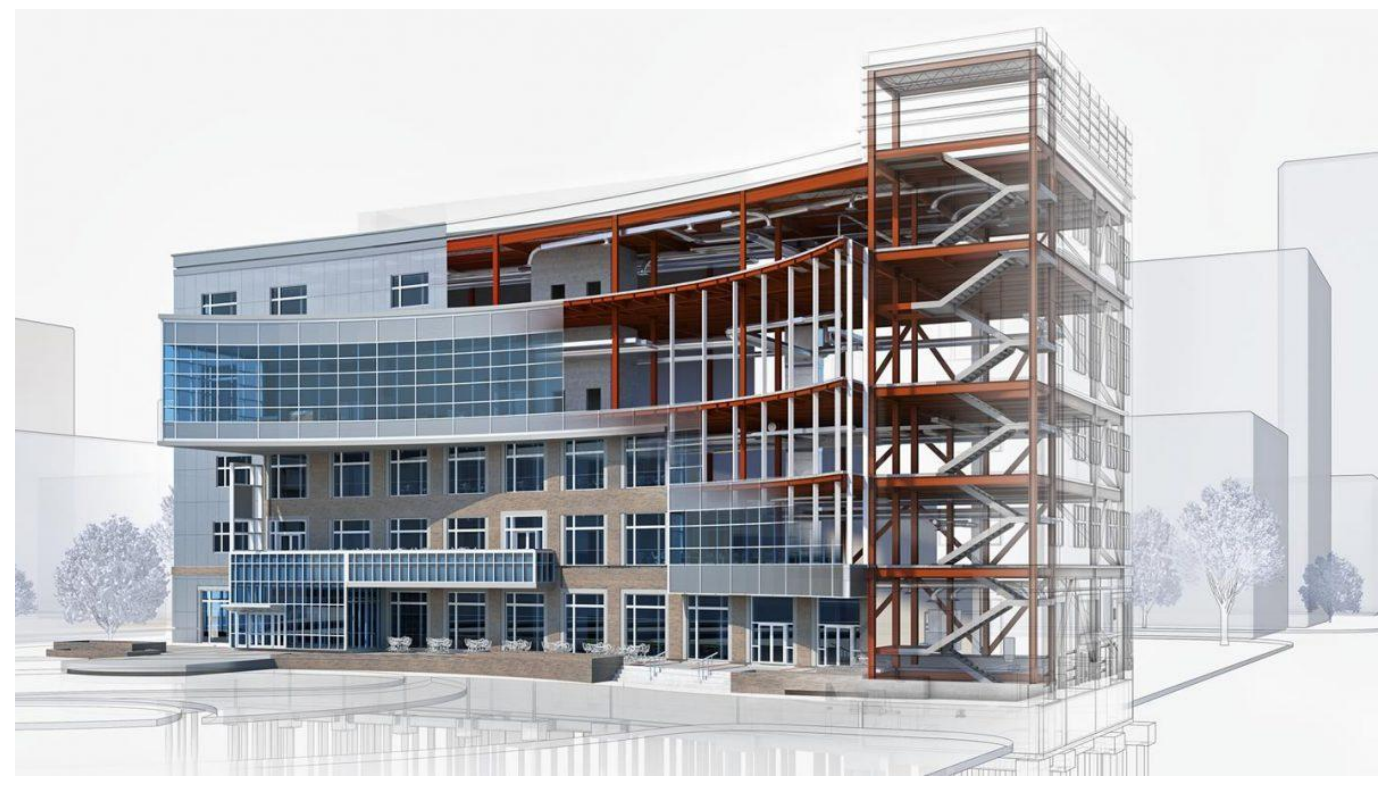

(Fonte: site tecnosilbr.com, acesso em 07/09/2020) 


\subsection{Internet das coisas}

A Internet das Coisas (Internet of Things - loT) é uma rede de objetos físicos que usam dispositivos eletrônicos como sensores e atuadores para corresponder e atualizar informações, a fim de obter ótimo desempenho por todos os sistemas utlizados.

A rede pode criar um feedback em tempo real para tomadas de decisão mais precisas. Esse sistema é geralmente referido como Telemática na indústria da construção e pode ser incorporada nos sistemas da uma construção ou edicifico para monitorar condições de operação, níveis de desempenho ou de estados físicos.

A loT muda a maneira como construímos, ocupamos e mantemos edifícios. Durante as fases de operação do edifício, os dados dos sensores loT podem ser integrados ao BIM usando dados para modelar tendências de ocupação, como uso de energia, inclinações de temperatura ou movimento de pessoas. A produção resultante dos modelos desenvolvidos pode ser examinada para aprimorar projetos futuros, além disso, um elemento essencial da loT é a conectividade.

"Como se fosse um grande sistema nervoso que possibilita a troca de informações entre dois ou mais pontos." (Proof, 2016)

Figura 3 - Internet da Coisas.

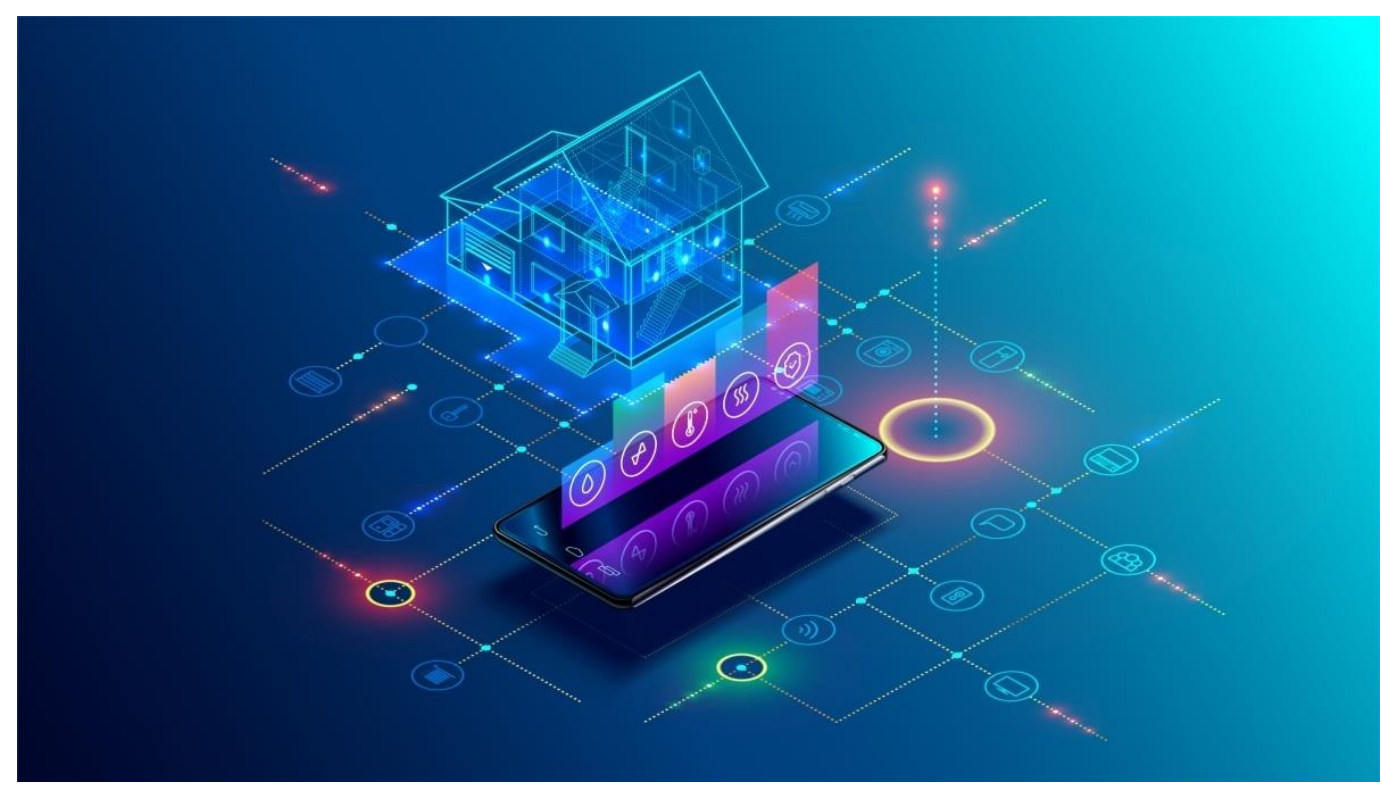

(Fonte: site bim-speed.eu, acesso em 07/09/2020) 


\subsection{Benefícios da industrialização das construções}

Ao implementar tecnologias avançadas de construção, a indústria da construção pode colher vários benefícios da IC. A IC pode resultar em custos trabalhistas reduzidos, melhoria na segurança, atrasos reduzidos, melhor qualidade do produto, maior produtividade e aumento da destreza, nenhum dos quais os métodos tradicionais de construção normalmente consegue alcançar.

"Em outras palavras, as inovações tecnológicas são aliadas importantes na redução, ou até eliminação de um dos maiores problemas do setor: o desperdício." (FIA, 2020)

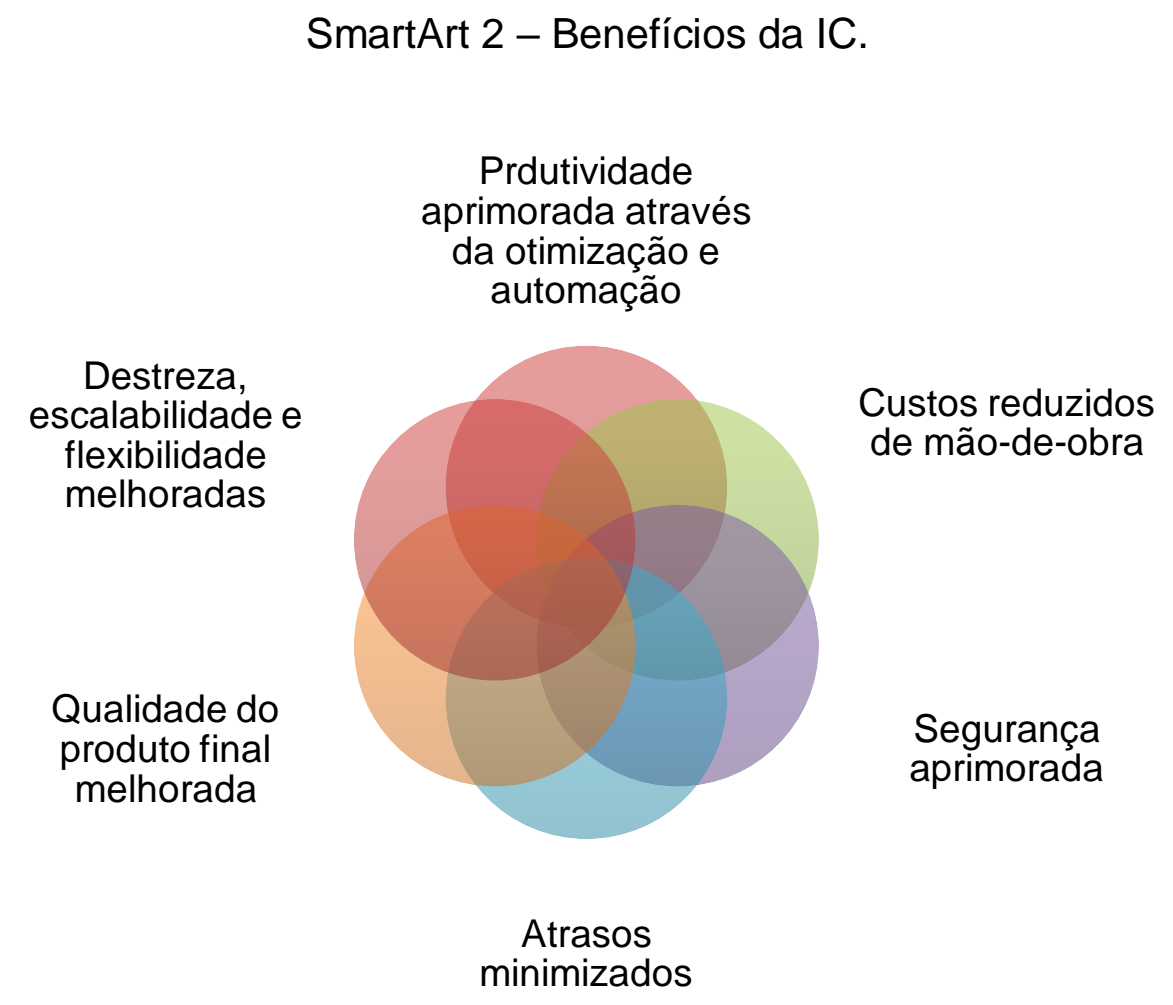

(Fonte: autor, realizado em 14/05/2020)

\section{Limitações da industrialização da construções}

A IC ainda é um sistema emergente de construção e, apesar de seu enorme potencial para fornecer soluções para os problemas previamente experienciados no setor, as limitações devem ser tratadas antes que a IC possa perturbar 
completamente o setor.

Alguns dos reveses críticos à adoção do $\mathrm{Cl}$ incluem aceitação social, altos custo gerais de construção, falta de mão de obra qualificada, pouco desenvolvimento, pesquisas, e falta de órgãos reguladores e de conformidade.

\section{SmartArt 3 - Limitações da IC.}

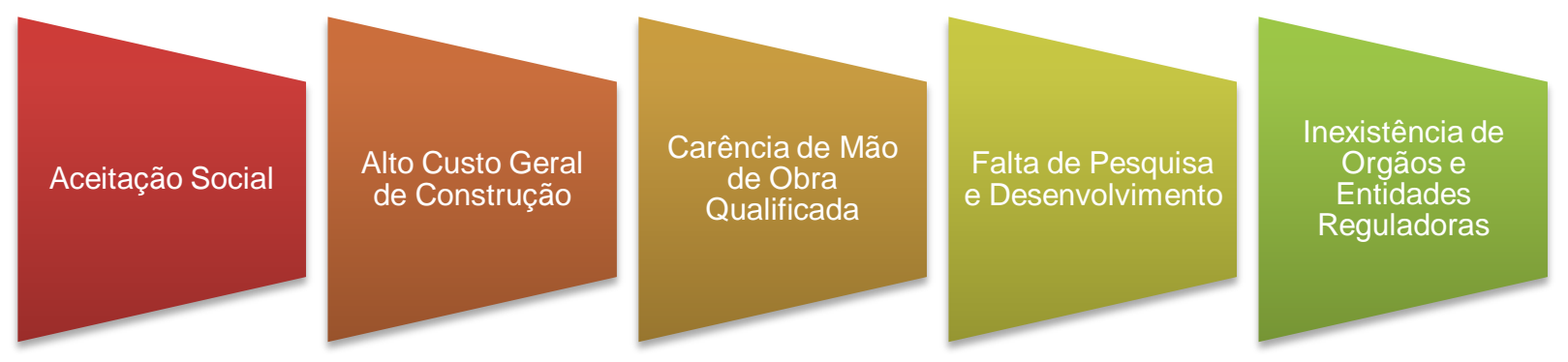

(Fonte: autor, realizado em 14/05/2020)

\section{Considerações Finais}

A digitalização e industrialização da construção foram identificados como chave para lidar com o declínio do nível de produtividade e baixa qualidade dos ativos na indústria. O mercado da construção civil cada vez mais incorpora tecnologias inovadoras, como sensores digitais, máquinas inteligentes e novos aplicativos de software integrados com uma plataforma central de BIM conectado em projetos de construção.

O futuro da indústria é altamente dependente da competência dos trabalhadores entrando na força de trabalho. Em face da perturbadora escassez de mão-de-obra qualificada, é crucial que novos funcionários entrem no setor com as habilidades e a exposição a tecnologias necessárias, para conduzir processos de Industrialização na Construção Civil e níveis mais altos de precisão na construção em geral.

A nova era da digitalização em construção oferece imensos benefícios para a indústria da construção, para meio ambiente e inclusive para a economia. Entretanto, apesar de diversas tecnologias avançadas de construção já estarem sendo integradas e do incrivel potencial envolvido, a implementação das mesmas 
em processos na indústria continua limitada, principlamente pela resistência do mercado a inovações tecnológicas.

\section{Referências}

DONIAK, Íria Lícia Oliva. (2012). Abic - Anuário 2012. Disponivel em: https://www.abcic.org.br/Arquivos/4plnmf0o.pdf. Acesso em: 06/10/2020.

FIA - Fundação Instituto de Administração. (2020). Tecnologia na Construção Civil: o que é, importância e exemplos. Disponivel em: https://fia.com.br/blog/tecnologia-na-construcao-civil/. Acesso em: 04/10/2020.

LIMA, Tomás. (2019). Como é o Uso de Robôs na Construção Civil. Disponivel em: https://www.sienge.com.br/blog/robos-na-construcao-civil/. Acesso em: 02/10/2020.

LIMA, Tomás. (2018). Entenda a importância da previsibilidade na Construção Civil. Disponivel em: https://www.sienge.com.br/blog/previsibilidadena-construcao-civil/. Acesso em: 20/09/2020.

LIMA, Victor Godeiro De Medeiros. (2016). SOBREPREÇO E SUPERFATURAMENTO DE OBRAS PÚBLICAS E INDICADORES EDUCACIONAIS: uma análise de suas relações nos Estados brasileiros. Disponivel em: https://repositorio.unb.br/bitstream/10482/20903/1/2016_VictorGodeirodeMedeiro sLima.pdf. Acesso em: 04/10/2020.

Overbr. (2019). Robôs na construção civil já é realidade. Disponivel em: https://overbr.com.br/atualidades/robos-na-construcao-civil-ja-e-realidade. Acesso em: 27/09/2020.

Proof. (2016). Internet das Coisas: Um Desenho do Futuro. Disponivel em: https://www.proof.com.br/blog/internet-das-coisas/. Acesso em: 26/09/2020.

Thórus Engenharia. (2020). Tudo sobre BIM: o que é, ferramentas e por onde começar [2020]. Disponivel em: https://thorusengenharia.com.br/blog/o-que-ebim/. Acesso em: 07/10/2020.

VIA - Estação Conhecimento. (2019). Inovação na construção civil: impressão 3D. Disponivel em: https://via.ufsc.br/inovacao-na-construcao-civil-impressao-3d/. Acesso em: 04/10/2020. 